\title{
A Rede de Agências Nacionais de Acreditação e a gestão do Sistema Arcu-Sul ${ }^{1}$
}

Gabriella de Camargo Hizume*

Gladys Beatriz Barreyro**

* (Universidade Estadual do Oeste do Paraná - Unioeste, Francisco Beltrão, Paraná, Brasil)

** (Universidade de São Paulo - USP, São Paulo, São Paulo, Brasil)
Resumo: Objetiva-se analisar a atuação da Rede de Agências Nacionais de Acreditação (Rana) na gestão do Sistema de Acreditação Regional de Cursos Universitários do Mercosul (Sistema Arcu-Sul). A Rana é composta por representantes das Agências Nacionais de Acreditação dos Estados participantes do Sistema. Os principais desafios da atuação da Rana envolvem desde a concepção de indicadores que sejam aptos a assinalar a qualidade de cursos pertencentes a sistemas de educação superior diferentes até a sua recomposição pela adesão de mais Estados. Foram utilizadas técnicas de pesquisa bibliográfica e documental, além de entrevistas com pessoas que participaram da elaboração do Sistema ou de ações relacionadas à Rana. Pode-se observar que a experiência de gestão da execução do Sistema possibilitou à Rana rever e flexibilizar alguns posicionamentos a fim de operacionalizar a consolidação do Sistema.

Palavras-chave: Rede de Agências Nacionais de Acreditação. Setor Educacional do Mercosul. Mercosul. Sistema Arcu-Sul.

O desenvolvimento deste trabalho contou com apoio da Fundação de Apoio à Pesquisa do Estado de São Paulo (Fapesp) e do Conselho Nacional de Desenvolvimento Científico e Tecnológico (CNPq). 


\section{INTRODUÇÃO}

Desde a criação do Mercado Comum do Sul (Mercosul), com o Tratado de Assunção de 1991, a educação tem sido considerada como um dos pilares da proposta de integração, entendendo-se que a elevação dos níveis educacionais na formação de recursos humanos é imprescindível para o desenvolvimento da região (HIZUME; BARREYRO, 2017). Nesta esteira, para coordenar as políticas educacionais nos Estados-membros e nos Estados Associados, no mesmo ano foi instituída a Reunião de Ministros de Educação (RME) com a Decisão 07/1991 do Conselho Mercado Comum².

Sob os auspícios da RME, o Setor Educacional do Mercosul (SEM) inicia suas atividades em fevereiro de 1992, em Buenos Aires, com a elaboração do primeiro Plano de Ação pelo Comitê Coordenador Regional do Setor Educação. Assim, o SEM foi composto como fórum específico para tratar da educação em todos os níveis e em suas dimensões regionais.

No SEM também se dirimem temas impulsionados pela internacionalização e regionalização da educação superior que demandam métodos e técnicas diferenciados, como a circulação de docentes, discentes, pesquisadores, pessoal técnico-administrativo e de profissionais diplomados. Neste particular, está envolvida uma série de questões que abordam desde a aferição da correspondência e comparabilidade da formação de nível superior até o estabelecimento de órgãos responsáveis pela gestão dessas ações.

Com a implementação do Mecanismo Experimental de Acreditação de Cursos para o Reconhecimento de Títulos de Graduação Universitária nos Países do Mercosul, Bolívia e Chile (Mexa), foi prevista uma nova instância dentro do SEM para geri-lo, a Rede de Agências Nacionais de Acreditação (Rana), formada por órgãos indicados por cada um dos Estados participantes denominados Agências Nacionais de Acreditação (ANAs), responsáveis pela execução dos procedimentos avaliativos a serem aplicados em âmbito interno.

A adoção da acreditação como política regional de certificação de qualidade de cursos de graduação e excelência acadêmica consolidou-se com a constituição do Sistema de Acreditação de Cursos de Graduação para o Reconhecimento Regional da Qualidade Acadêmica dos Respectivos Diplomas no Mercosul

O Conselho Mercado Comum é o órgão superior do bloco, incumbido da condução política do processo de integração e da tomada de decisões para o cumprimento dos objetivos do Tratado de Assunção e dos demais tratados. 
e Estados Associados (Sistema Arcu-Sul) em 2008, derivado do Mexa e de caráter permanente. O Sistema Arcu-Sul não apenas fortalece a Rana como órgão gestor, como também lhe lança desafios em virtude de sua expansão. Nesse contexto, o presente trabalho se propõe a analisar a atuação da Rana na condução do processo de acreditação regional mercosulino.

\section{A FORMAÇÃO DA RANA}

Embora a cultura da avaliação e da acreditação da educação superior não estivesse amplamente consolidada ou fosse inexistente em alguns países do Mercosul, em 1996, iniciaram-se os trabalhos para verificar a possibilidade do estabelecimento de um sistema de acreditação de títulos de graduação que viabilizasse a comparabilidade dos processos de formação acadêmica e que pudesse favorecer o deslocamento de profissionais qualificados portadores de diplomas de ensino superior e estimular a qualidade educacional na região.

A partir das atividades do Grupo de Trabalho de Especialistas em Acreditação e Avaliação da Educação Superior (GTEAE), foi apresentada a primeira proposta de regulação da matéria regionalmente que deu origem ao Memorando de Entendimento sobre a Implementação de um Mecanismo Experimental de Acreditação de Cursos para o Reconhecimento de Títulos de Graduação Universitária nos países do Mercosul (Mexa) de 1998, assinado pelos integrantes da RME e dos Estados Associados Bolívia e Chile (FULQUET, 2006).

O Memorando trazia os princípios gerais do processo de acreditação, como a participação voluntária das Instituições de Ensino Superior (IES) e o respeito a sua autonomia e às legislações nacionais, a definição de termos técnicos para fins operacionais, os procedimentos avaliativos que comporiam o processo de acreditação e as instâncias responsáveis por sua execução e gestão. Sucintamente, o processo de acreditação abarcaria como procedimentos: a autoavaliação, realizada pela IES à qual o curso a ser acreditado pertenceria; a avaliação externa, realizada por um Comitê de Pares; e, por fim, a expedição do ditame de acreditação. As fases do processo se dariam tanto em âmbito nacional quanto regional; internamente, a implementação dos procedimentos de cunho avaliativo ficaria sob a responsabilidade das Agências Nacionais de Acreditação (ANAs) e a coordenação geral do processo sob a incumbência das Agências organizadas em rede, a Rana. Assim, tem-se um novo ator que, individualmente, tem competências para atuar dentro de determinado Estado na implementação de políticas públicas educacionais regionais e que, 
regionalmente, pode tanto representar seu Estado de origem por delegação ou agir coletivamente em rede, gerindo o processo regional e, consequentemente, passando a integrar o Setor Educacional do Mercosul (SEM).

As ANAs, além da indicação dos Estados, deveriam se constituir como pessoa de direito público interno, ter caráter coletivo em sua conformação, ser compostas por membros idôneos e ter respeitada a autonomia de suas decisões.

A criação das ANAs consta do Plano Trienal 1998-2000 do SEM ${ }^{3}$, que tem toda a meta IV do "Compromisso de Brasília: metas do Plano Trienal para o ano de 2000"4 dedicada ao Mexa, trazendo como previsão:

A constituição de Agências Nacionais de Acreditação em todos os Estados-membros, para avaliar, acreditar, acompanhar cursos e programas de graduação, no quadro do Memorando de Entendimento sobre a Implementação do Mexa (MERCOSUR EDUCATIVO,

Além de indicar os órgãos que fariam as vezes de ANA, os Estados assumiram o compromisso de facilitar projetos de monitoramento e cooperação entre as Agências, estabelecendo-se regionalmente a Rana. A Rede também ficou responsável por promover uma meta-avaliação do Mexa.

O Mecanismo foi revisto em 1999, trazendo a maioria das emendas e ajustes em relação ao Comitê de Pares, reduzido a três membros, sendo um do Estado do curso em avaliação e dois de outros Estados participantes (ANDRÉS, 2010). Embora a participação de pares estrangeiros no procedimento de avaliação externa consubstancie não apenas a integração, mas sua construção coletiva, poderá obstaculizar as atividades das ANAs, exigindo um posicionamento futuro da Rana (HIZUME; BARREYRO, 2017).

Antes da elaboração da versão final do Mexa, foi aplicado um pré-teste entre os anos de 1998 e 2000 para verificar a adequação dos critérios e dos indicadores, e, especialmente, a operacionalidade do processo. Foram definidos os cursos de Agronomia, Engenharia e Medicina pela RME e cada Estado participante

3 Inicialmente, a proposta do SEM era que fossem elaborados Planos Trienais, mas passaram a ser quinquenais a partir de 2001, tendo em vista a expansão das atividades desenvolvidas. Observa-se, também, que a terminologia para esse tipo de documento varia, sendo uns chamados de Planos de Ação e outros de Planos Estratégicos.

4 O Plano Trienal 1998-2000 é composto de três partes: 1) Termos de Referência para a definição do Plano Trienal do Setor Educacional do Mercosul 1998-2000; 2) Plano Trienal 1998-2000 do Setor Educacional do Mercosul e 3) Compromisso de Brasília: Metas do Plano Trienal para o ano 2000. 
poderia indicar até duas IES para cada um dos cursos (HERMO, 2011), passando pelo pré-teste as Universidades listadas no quadro abaixo.

Quadro 1 - Instituições de Ensino Superior por curso e país que participaram do préteste para o Mexa

\begin{tabular}{|c|c|c|}
\hline Curso & País & Universidade \\
\hline \multirow{5}{*}{ Agronomia } & Argentina & Universidad Nacional de Mar del Plata \\
\hline & Brasil & Universidade Federal de Lavras \\
\hline & Chile & Universidad Austral de Chile \\
\hline & Paraguai & Universidad Nacional de Asunción \\
\hline & Uruguai & Universidad de la República \\
\hline \multirow{4}{*}{ Engenharia } & Argentina & Universidad Católica de Córdoba \\
\hline & Brasil & Universidade Estadual de Campinas \\
\hline & Chile & Universidad Católica de Valparaíso \\
\hline & Paraguai & Universidad Católica de Asunción \\
\hline \multirow{5}{*}{ Medicina } & Argentina & Medicina Universidad del Salvador \\
\hline & Bolívia & Universidad Mayor de San Simón \\
\hline & Brasil & Universidade Federal de São Paulo \\
\hline & Chile & Universidad de Valparaíso \\
\hline & Paraguai & Universidad Nacional de Asunción \\
\hline
\end{tabular}

Fonte: Hizume (2013).

De acordo com entrevistados da Argentina, Brasil e Paraguai ${ }^{5}$, a escolha desses três cursos se deu por consenso por representarem carreiras clássicas, que exigem diploma universitário, de áreas distintas e de caráter universal, isto é, sem vinculação estrita a contextos nacionais como o curso de Direito, por exemplo. Deve-se observar, também, que o foco na graduação se daria por ser o grau acadêmico mínimo de formação exigido para o exercício profissional.

Dos Estados fundadores do bloco, com exceção da Argentina, cuja agência, a Comisión Nacional de Evaluación y Acreditación Universitaria (Coneau), foi instituída em 1995, os demais Estados participaram por meio de comissões ad hoc ou de órgãos do sistema nacional de educação superior, de acordo com Hizume (2013).

A partir do pré-teste, o Mexa foi novamente revisado e em 2002 foi aprovada a última versão do Memorando, que substituiu a de 1998. As ANAs aparecem

5 Foram entrevistadas 11 pessoas que participaram da elaboração do Sistema Arcu-Sul ou de ações relacionadas à Rana, sendo quatro da Argentina e do Brasil e três do Paraguai. 
como cerne do processo de acreditação, passando a dispor de maior autonomia, refletida na discricionariedade para determinar os procedimentos avaliativos internos, seus trâmites e normas, desde que estivessem em conformidade com as normas gerais do Mecanismo reguladas pela Rana. Segundo Hermo (2011), a Rana teria sido criada nesta oportunidade como órgão gestor do Mexa.

As atividades internas das ANAs abarcavam desde o lançamento de convocatórias, a escolha de critérios para selecionar os cursos que passariam pelo Mexa, e assistir tecnicamente as atividades de aplicação dos procedimentos avaliativos até elaborar um Manual de Autoavaliação. Esta última função considerava as diferenças entre os sistemas educacionais nacionais e as distintas culturas avaliativas, visando, posteriormente, a convergência dessas normas e a elaboração de um Guia de Autoavaliação. À Rana coube, além da deliberação dos procedimentos gerais e a outorga do ditame de acreditação, a elaboração e disponibilização do cadastro de pares avaliadores para consulta das ANAs e das IES. A capacitação dos pares seria oferecida pelas ANAs ou pela Rana em formato de oficinas.

A aplicação do Mexa, prevista no Plano Estratégico 2001-2005, deu-se entre os anos de 2002 e $2006^{6}$, e ao final foram acreditados 62 cursos -19 de Agronomia, 29 de Engenharia e 14 de Medicina -, como pode ser observado no quadro a seguir.

Quadro 2 - Cursos acreditados por Estado no Mexa

\begin{tabular}{|c|c|c|c|c|c|c|c|}
\hline $\begin{array}{l}\text { Estado } \\
\text { Curso }\end{array}$ & Argentina & Brasil & Paraguai & Uruguai & Bolívia & Chile & Total \\
\hline Agronomia & 5 & 3 & 1 & 1 & 4 & 5 & 19 \\
\hline Engenharia & 6 & 6 & 6 & 5 & 6 & 0 & 29 \\
\hline Medicina & 3 & 3 & 1 & 1 & 3 & 3 & 14 \\
\hline Subtotal & 14 & 12 & 8 & 7 & 13 & 8 & 62 \\
\hline
\end{tabular}

Fonte: Hizume (2010).

Insta notar que embora fosse esperado que os Estados já tivessem preparado suas ANAs para participar do Mexa até 2000, como aponta Andrés (2010), considerando-se o trabalho que vinha sendo desenvolvido pelas Comissões

6 Há divergência nas informações em relação ao período em que o Mexa foi aplicado. Em documentos oficiais, como o Manual do Sistema Arcu-Sul de 2008 e o Manual de Procedimentos do Sistema, consta o período de 2004 a 2006 (MERCOSUR, 2008, 2015), enquanto em trabalhos acadêmicos encontram-se registros de atividades em 2002 , como em Hermo (2011) e Guilayn (2012). 
Consultivas por área com representantes de todos os Estados participantes, Brasil7, Paraguai e Uruguai continuaram indicando comissões ad hoc ou órgãos de seu sistema nacional no Mecanismo. No Paraguai, o Mexa foi assumido pela Agencia Nacional de Evaluación y Acreditación de la Educación Superior (Aneaes), criada pela Lei n. 2072, de 2003, em função do processo de acreditação regional.

Não obstante este cenário e a ausência de documentação que precise o momento de criação da Rana, pode-se considerar que é no Mexa que a Rede é delineada e assume os contornos de órgão coordenador do processo de acreditação regional de natureza sui generis colegiada, composto por órgãos chancelados pelos ordenamentos jurídicos nacionais para desempenhar funções transnacionais (HIZUME, 2013).

Como previsto, em 2006 a Rana realizou a meta-avaliação do Mexa, contando com a participação dos representantes das ANAs, das IES, dos pares avaliadores e dos experts que participaram das Comissões e dos Grupos de Trabalho. 0 processo de acreditação foi reconhecido como importante fator para a integração e para a melhora da qualidade da educação na região, propondo-se um sistema de acreditação permanente nos mesmos moldes do Mexa (MERCOSUR, 1998, 2015).

Dando seguimento à indicação da acreditação de qualidade de cursos de graduação como política pública regional do bloco, em 2007 foi elaborado o Memorando de Entendimento para a criação e implementação de um Sistema de Acreditação de Cursos Universitários para o Reconhecimento das Respectivas Titulações no Mercosul e Estados Associados, que se transformou no Acordo sobre a criação e implementação de um Sistema de Acreditação de Cursos Universitários para o Reconhecimento da Qualidade Acadêmica das Respectivas Titulações no Mercosul e Estados Associados, aprovado pela Decisão 17/2008 do Conselho Mercado Comum, que criou o Sistema ArcuSul, conforme previsto no Plano de Ação 2006-2010 do SEM (HIZUME, 2013).

O Sistema foi apresentado como instrumento para proporcionar 0 desenvolvimento econômico, social, político e cultural da região à medida que incentiva a melhora da qualidade dos cursos universitários e, também, para viabilizar a circulação de pessoal acadêmico, a cooperação interinstitucional e programas de mobilidade, com base na cooperação solidária. Estimava-

No Mexa, a Secretaria de Educação Superior (Sesu) e o Conselho Nacional de Educação (CNE) atuaram como ANA, organizando o processo de acreditação. 
se a promoção da melhora da qualidade educacional regional pelo fato de o Sistema trazer como um de seus princípios que os critérios e perfis de qualidade devem ser tão ou mais exigentes que os aplicados nos países, consistindo a acreditação em garantia pública de qualidade, válida por seis anos (MERCOSUR, 2015). Já a circulação de trabalhadores egressos dos cursos acreditados no Mercosul passa para uma fase posterior que o Sistema não abrange, notando-se que a acreditação não autoriza, explicitamente, o exercício profissional; isso dependeria do reconhecimento de títulos e da autorização dos respectivos conselhos de classe (BARREYRO; HIZUME, 2017). No Plano Estratégico 2011-2015 do SEM, o reconhecimento de títulos foi considerado como valor agregado do processo de acreditação, para o qual deveria ser elaborado um mecanismo próprio (MERCOSUR, 2012).

Embora a Rana se firme enquanto órgão do SEM com o Sistema Arcu-Sul, tendo em vista a especificidade provisória do Mexa, é a partir desse momento que passa a enfrentar os maiores desafios, pois se o Mexa possuía limitações decorrentes de seu caráter experimental, ao ser adotado o mesmo modelo para o sistema permanente, a expansão do processo de acreditação regional e sua aplicação em larga escala restam prejudicadas em face de questões pouco claras, como a sua forma de financiamento e o custoso procedimento de avaliação externa envolvendo pares estrangeiros; acrescente-se a esse quadro o fato de que, apesar do compromisso assumido pelos Estadosmembros do bloco, Brasil $^{8}$ e Uruguai ${ }^{9}$ ainda não haviam constituído suas ANAs de acordo com o prescrito nas normas regionais, como ainda não o fizeram.

Antes de adentrar na atuação da Rana na gestão do Sistema Arcu-Sul,

8 Para o Sistema Arcu-Sul, o Brasil nomeou, em um primeiro momento, a Comissão Nacional de Avaliação da Educação Superior (Conaes) como ANA. Contudo, dada sua falta de estrutura para aplicar internamente os procedimentos avaliativos, por meio da Portaria n. 1.734 do Ministério da Educação, de 9 de dezembro de 2011, o Instituto Nacional de Estudos e Pesquisas Educacionais Anísio Teixeira (Inep) e a Secretaria de Regulação e Supervisão da Educação Superior (Seres) foram nomeados junto à Conaes para exercer a função de ANA, sendo expedida a primeira acreditação brasileira pelo Sistema Arcu-Sul apenas em 2013 (HIZUME, 2013). Deve-se notar que desde 2012 tramita no Congresso Nacional, em regime de prioridade, o Projeto de Lei n. 4.372/2012 sobre a criação do Instituto Nacional de Supervisão e Avaliação da Educação Superior (Insaes). Este novo órgão traria, entre suas incumbências, o exercício da função de ANA, atendendo às demandas regional e internacional. Deve-se notar, ainda, que no Brasil não há instituto correspondente à acreditação. A prática que mais se assemelharia seria a da avaliação da Coordenação de Aperfeiçoamento de Pessoal de Nível Superior (Capes) em relação aos cursos de pós-graduação.

9 O Uruguai continua atuando por meio de comissões ad hoc, enquanto tramita, desde 2009, o Projeto de Lei para a criação da Agencia para la Promoción y Aseguramiento de la Calidad de la Educación Terciaria (Apacet). 
passamos à discussão de sua institucionalização como órgão vinculado ao Setor Educacional do Mercosul.

\section{A RANA NA ESTRUTURA DO SEM}

O SEM passou por duas reestruturações em função do alargamento das atividades previstas em seus Planos de Ação. Em sua formação original, contava com apenas três órgãos: a Reunião de Ministros da Educação (RME), a Secretaria pro tempore e o Comitê Coordenador Regional (CCR). A RME figurava como instância máxima, enquanto a Secretaria pro tempore era a responsável pela parte operacional, com a função de organizar a agenda das reuniões dos ministros e verificar o andamento dos acordos e trabalhos do Setor ${ }^{10}$, e o Comitê Coordenador Regional organizava ações específicas.

$\mathrm{Na}$ primeira reestruturação, de 2000, foram acrescidas a Comissão Regional Coordenadora da Educação Básica (CRC-EB), a Comissão Regional Coordenadora da Educação Superior (CRC-ES) e a Comissão Regional Coordenadora da Educação Tecnológica (CRC-ET), encarregadas de definir as políticas para cada área (HERMO, 2011). Também passou a integrar o SEM o Comitê Gestor do Sistema de informação e Comunicação (CGSIC), incumbido de gerenciar o Sistema de Informação e Comunicação (SIC), responsável por disponibilizar informações atualizadas e confiáveis sobre os sistemas educacionais dos Estados-membros e Associados com o fim de viabilizar o acompanhamento das políticas públicas regionais de educação.

A segunda reestruturação orgânica do SEM foi trazida pelo Plano de Ação 2011-2015, que institucionalizou os Grupos de Trabalho e criou a Comissão Regional Coordenadora de Área para Formação Docente (CRC-FD). De forma geral, os órgãos permanecem com as mesmas funções, considerando-se como principais a política, a técnica e a executiva. A RME e o CCR ficaram a cargo da tarefa política; com as Comissões Regionais Coordenadoras de Área e com o Comitê Assessor do Fundo de Financiamento do SEM (Cafem), a técnica; e a executiva, com os Grupos de Trabalho (GTs), Grupo Gestor de Projetos (GGP), Comissões ad hoc, Comitê de Gestão e CGSIC, observando-se que os GTs e o GGP possuem caráter temporário.

Embora o texto do Plano que justifica as alterações não mencione, no novo organograma, abaixo reproduzido, constam três outros órgãos: 1) o Comitê

10 Ocupada em consonância com o sistema oficial executivo do Mercosul em ordem alfabética, seguindo o nome dos Estados-membros do bloco. 
Assessor de Políticas Linguísticas (CAPL), no mesmo patamar do CGSIC e do Cafem; 2) a Comissão Técnica Regional do Protocolo de Integração Educativa e Reconhecimento de Certificados, Títulos e Estudos de Nível Primário e Médio não técnico (CTR-Protocolo) ${ }^{11}$, ligado à CRC-EB; 3) e a Rana, vinculada ao CRC-ES.

Figura 1 - Novo organograma do SEM

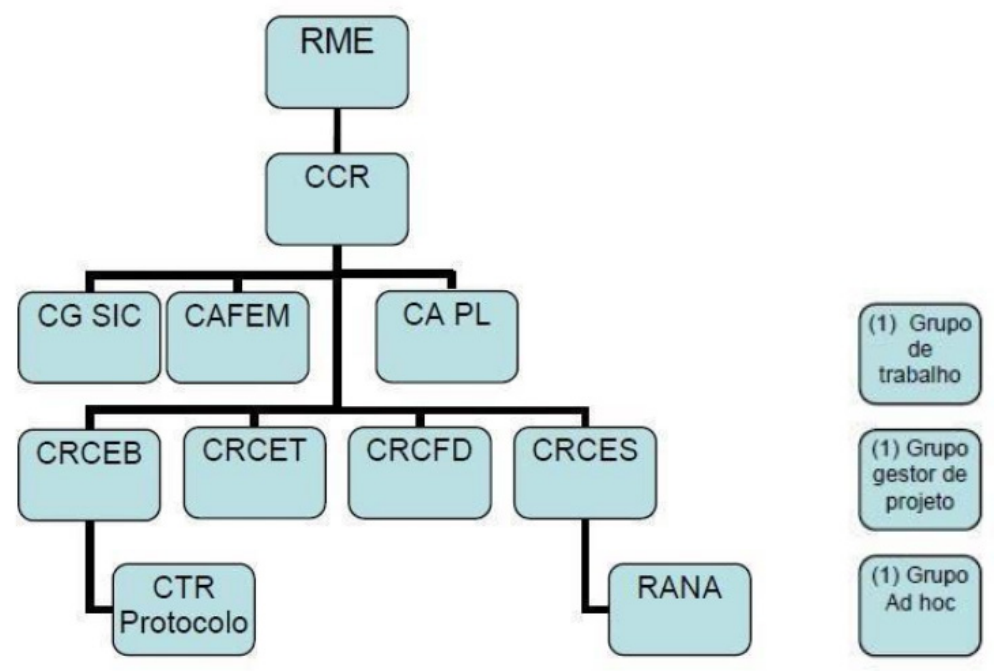

Fonte: Plano de Ação 2011-2015.

Conquanto metas sejam relacionadas à CAPL, ao CTR-Protocolo e à Rana, em nenhum momento se discorre sobre quais sejam as suas atribuições no SEM. 0 artigo 1ํ do documento Estrutura Orgânica e Regulamento Interno do Setor Educacional do Mercosul, constante do Anexo II do Plano, apresenta a seguinte redação:

Art. 1ํ․ A estrutura orgânica do Setor Educacional do Mercosul (SEM) conta com os seguinte âmbitos:

- Reunião de Ministros de Educação (RME);

- Comitê Coordenador Regional (CCR);

- Comissões Regionais Coordenadoras de Área (CRCA);

- Grupos de Trabalho (GT);

- Grupos Gestores de Projetos (GGP);

- Comitê de Gestão do Sistema de Informação e Comunicação (CGSIC);

- Comitê Assessor do Fundo de Financiamento do Setor Educacional do Mercosul (Cafem);

- Comitê Assessor de Políticas Linguísticas (CAPL);

- Comissões Ad hoc (MERCOSUl EDUCACIONAL, 2011).

${ }_{11}$ Somente foi possível identificar a definição da sigla no Index de Instancias del Sector Educativo del Mercosur 2012. 
Mais uma vez, o CTR-Protocolo e a Rana não são sequer mencionados, e a CAPL é apenas listada. O site oficial do Mercosul Educacional, ao discorrer sobre as instâncias que compõem a estrutura do SEM, exibe um organograma diverso do constante do Plano 2011-2015, mais detalhado, em que todas as instâncias estão de alguma forma interligadas.

Figura 2 - Organograma do SEM do site do Mercosul Educacional

\section{SETOR EDUCACIONAL DO MERCOSUL}

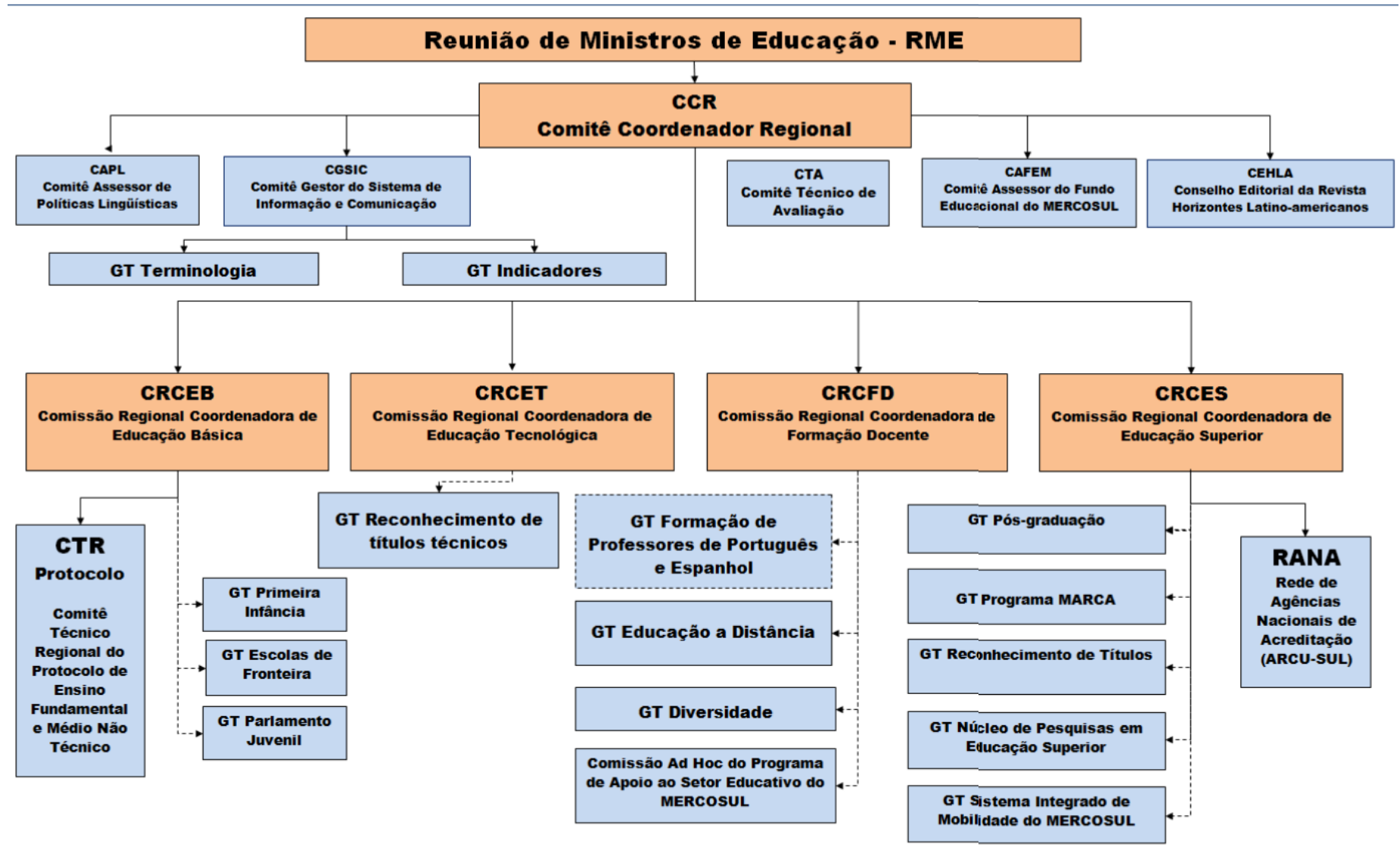

Fonte: Mercosur Educativo, 2017a.

A exata compreensão dos órgãos que compõem o SEM, suas funções, estruturas e atuação, é dificultada pela falta de sistemática na organização dos documentos oficiais, seja por seu conteúdo, localização, disponibilidade, e até mesmo tradução para o português, perdendo-se em um emaranhado de informações dispersas e algumas vezes contraditórias. 0 posicionamento da Rana logo abaixo do CRC-ES, separadamente dos GTs de Educação Superior e em posição de destaque, denota seu caráter de órgão do SEM (HIZUME, 2013).

Para Guilayn (2012), com este Plano o RME oficializa a posição da Rana no SEM, que apesar de não ter sua origem devidamente documentada em 
decisões dos ministros, teve sua primeira reunião em abril de 2001, sendo denominada inicialmente Reunião de Agências Nacionais de Acreditação. Este também é o indicado por um dos entrevistados ${ }^{12}$ como 0 ano de criação do órgão, mencionando um seminário ocorrido em Santiago do Chile em que as novas instâncias da primeira modificação na estrutura do SEM, esquematizadas no final do ano 2000, começaram a operar. Cita o entrevistado uma reunião realizada em setembro de 2001, em Santiago, em que pela última vez se contou com a participação das comissões consultivas e grupos de trabalho para o Mexa e foi consignada a Rana. Pode-se aferir de sua fala que a criação da Rana significou um avanço para a implantação do processo de acreditação, implicando a extinção de trabalhos difusos para a criação do Mexa, concentrando ações. Assim, seriam aproximadamente dez anos de atuação nos bastidores coordenando a principal política pública do bloco para a educação superior, já que há registros no site oficial do Mercosul Educacional de atas da Rana que datam a partir de $2002^{13}$. A conversão de Reunião em Rede se dá, conforme Guilayn (2012), com a decisão da RME de criar o Sistema Arcu-Sul a partir de 2007.

Do item II.3 da Decisão 17/2008 que instaura o Sistema Arcu-sul, é possível ter-se o entendimento de que a Rana teria sido criada nesta oportunidade, como se pode observar:

Item II. 3. As Agências Nacionais de Credenciamento ${ }^{14}$, órgãos executivos do Sistema ARCUSUL, serão organizadas como uma Rede que criará suas próprias regras de funcionamento e adotará decisões por consenso (MERCOSUL, 2008a).

Ainda sobre a procedência da Rana, 2006 é o ano apontado pelo site oficial do Mercosur Educativo no tópico Que es el Sector Educativo del Mercosur (MERCOSUR, 2017b), ou seja, são cotejadas neste texto três fontes oficiais que ensejam diferentes indicações sobre a época de fundação de um órgão, o que implica a descontextualização do desenvolvimento e importância de institutos que são tomados como diretrizes para determinada área, no caso, a educação superior para o próprio SEM.

12 Entrevistado para a pesquisa não identificado em respeito às normas de ética para a pesquisa envolvendo seres humanos, constando de cláusula expressa ao Termo de Consentimento Livre e Esclarecido.

13 A primeira Ata que consta do site do Mercosul Educativo como da RANA é a n. 01/2002, "Acta de la I Reunión de la Comisión Ad Hoc del Sector Educativo del Mercosur sobre Acreditación de Professores de Idioma”.

14 Até 2011, o termo em espanhol acreditación vinha sendo traduzido para o português como “credenciamento”, passando, a partir de então, a ser utilizado o termo "acreditação”. 
O Sistema Arcu-Sul traz como características principais seu caráter perene e as missões de ampliar a aplicação do processo de acreditação regional e de conferir significado ao ditame de acreditação além do simbólico, cabendo à Rana a incumbência de implementá-lo.

O Plano de Ação 2011-2015 coloca a Rana na posição de propulsora dos objetivos estratégicos previstos para os cursos de graduação na medida em que se almeja firmar o Sistema Arcu-Sul, do qual dependem outros programas e a solução para a controvérsia do reconhecimento de títulos, vinculando-se diretamente aos objetivos 2, promover a educação de qualidade para todos como fator de inclusão social, de desenvolvimento humano e produtivo, e 4, promover e fortalecer os programas de mobilidade de estudantes, estagiários, docentes, gestores, diretores e profissionais.

Relativamente à ampliação do Sistema, o Plano prevê a participação de um número maior de instituições e cursos e sua utilização, enfim, como instrumento para o reconhecimento de títulos, no objetivo específico 4, prevendo que ao final do primeiro ciclo do Sistema sejam acreditados 500 cursos.

O fortalecimento do Sistema Arcu-Sul integra o segundo objetivo específico ao lado de ações correlatas, voltadas para a promoção da formação para a docência universitária, da colaboração regional de experiências em educação a distância, do fomento à pesquisa sobre vínculos entre as IES com os sistemas produtivos locais, de políticas de qualidade na educação da pós-graduação e, por fim, da consolidação do processo de garantia da qualidade mediante 0 incremento da visibilidade e confiabilidade do processo de acreditação. Assim, estipulam-se como ações a elaboração e publicação de convocatórias para aumentar o número de cursos que possibilitem o fomento da circulação de profissionais, a partir do reconhecimento de títulos, buscando-se contemplar todas as áreas de conhecimento.

Para a promoção e consolidação do processo de garantia e qualidade, quatro são as metas: formar recursos humanos e intercâmbios de experiências institucionais entre os atores envolvidos; definir critérios básicos para alcançar uma gestão eficiente, com maior visibilidade e confiabilidade; avaliar o Sistema Arcu-Sul com vistas à sua expansão e diversificação e promover a ratificação ${ }^{15}$ do Acordo que institui o Sistema Arcu-Sul entre os Estados participantes.

15 No direito internacional, o instituto da ratificação representa o compromisso assumido pelos Estados em cumprir tratados. 
A fim de atingi-las, as ações consignadas envolvem o desenho e a implementação de programas de intercâmbio, a criação de sistema virtual de suporte ao Sistema, a promoção e o aumento da visibilidade do Sistema nacional e internacionalmente, a realização de seminários, a apresentação de propostas para a reforma do Sistema e, por fim, a promoção da ratificação do Acordo que cria o Sistema Arcu-Sul pelos Estados participantes, principalmente os membros do bloco, a fim de cumprir os requisitos previstos no próprio Acordo para sua entrada em vigência, isto é, a ratificação por quatro Estados-membros. Pela complexidade das ações, várias tinham como prazo previsto para sua consecução o último ano de vigência do Plano, isto é, 2015, mas algumas, aparentemente mais simples, como a realização de Seminário de Autoavaliação do Sistema e a promoção da ratificação do Acordo, propostas para 2011, foram realizadas extemporaneamente ou simplesmente não ocorreram.

O quarto objetivo, pertinente à promoção e ao fortalecimento de programas de mobilidade de estudantes, estagiários, docentes, gestores, diretores e profissionais, reflete a busca por um significado, além do simbólico, para a acreditação regional, isto é, auferirem-se efeitos materiais à certificação de qualidade, já que reconhecer a qualidade de per si, a priori, acarreta somente prestígio para o curso e um possível aumento de sua procura.

O reconhecimento de títulos interpola, desde o início, as discussões sobre a acreditação dos cursos de graduação, e a previsão de ações no Plano 20112015 para sua concretização simboliza os esforços envidados para a abertura de dimensões reais para os trabalhadores portadores de diplomas de nível superior e acadêmicos na região. 0 objetivo específico sobre o tema consiste em contribuir para a livre mobilidade de profissionais, por meio de acordos marcos de reconhecimento de títulos de cursos acreditados, que trazem como meta a implementação de mecanismos de reconhecimento de títulos ao menos para três dos cursos acreditados, provavelmente Agronomia, Engenharia e Medicina, por terem participado desde o Mexa. 0 resultado esperado é o Mecanismo Regional de Reconhecimento de Títulos aprovado, ao menos, para esses três cursos.

Se por um lado o Plano demonstra a intenção de consolidar o Sistema ArcuSul, dilatando o rol de ações a ele atreladas e demandando uma operosidade maior da Rana, por outro, o acompanhamento do processo de acreditação e da implementação do Sistema Arcu-Sul, independentemente de meta-avaliações oficiais, tem demonstrado limitações cruciais de ordem operacional, sinalizadas pela atuação das ANAs, envolvendo desde o financiamento 
até a quebra de confiança na execução dos procedimentos acreditatórios, colocando em risco, assim, a continuidade de toda uma arquitetura concebida para a educação superior, segundo vários dos entrevistados.

Atualmente, tem-se que o Sistema Arcu-Sul, encontra-se com convocatórias abertas para seu segundo ciclo ${ }^{16}$. 0 primeiro ciclo foi aplicado entre os anos de 2008 e 2014, sendo acreditados 235 cursos (muito aquém dos 500 previstos no Plano). O Sistema continua em expansão, contando com a participação do Equador e com o acréscimo dos cursos de Economia, Farmácia e Geologia (MERCOSUL, 2015).

No quadro a seguirpode-se observaro desenvolvimento do sistema de acreditação mercosulino, notadamente a expansão de Estados participantes e de cursos.

16 Constam do site do Sistema Arcu-Sul as convocatórias da Argentina para o curso de Arquitetura, do Chile e do Uruguai para Agronomia e Arquitetura (SISTEMA ARCU-SUR, s/d). 
Quadro 3 - Expansão da acreditação de cursos de graduação no Mercosul

\begin{tabular}{|c|c|c|c|c|}
\hline & $\begin{array}{c}\text { Estados } \\
\text { participantes }\end{array}$ & Cursos & $\begin{array}{c}\text { Número } \\
\text { de cursos } \\
\text { acreditados }\end{array}$ & Período \\
\hline Mexa & $\begin{array}{c}\text { Argentina } \\
\text { Brasil } \\
\text { Paraguai } \\
\text { Uruguai } \\
+ \\
\text { Bolívia e } \\
\text { Chile } \\
\text { (6) }\end{array}$ & $\begin{array}{l}\text { Agronomia } \\
\text { Engenharia } \\
\text { Medicina } \\
\text { (3) }\end{array}$ & $\begin{array}{c}19 \\
29 \\
14 \\
\text { Total: } 62\end{array}$ & $2002-2006$ \\
\hline $\begin{array}{l}\text { Sistema } \\
\text { Arcu-Sul } \\
\text { 10 Ciclo }\end{array}$ & $\begin{array}{c}6 \\
+ \\
\text { Colômbia e } \\
\text { Venezuela } \\
\text { (8) }\end{array}$ & $\begin{array}{l}\text { Agronomia } \\
\text { Arquitetura } \\
\text { Enfermagem } \\
\text { Engenharia } \\
\text { Medicina } \\
\text { Odontologia } \\
\text { Veterinária } \\
\text { (7) }\end{array}$ & \begin{tabular}{|c|}
36 \\
22 \\
78 \\
21 \\
11 \\
26 \\
Total: 235 \\
Previsão: 500 \\
\end{tabular} & 2008-2014 \\
\hline $\begin{array}{l}\text { Sistema } \\
\text { Arcu-Sul } \\
2^{\circ} \text { Ciclo }\end{array}$ & $\begin{array}{c}8 \\
+ \\
\text { Equador } \\
\text { (9) }\end{array}$ & $\begin{array}{c}\text { (7) } \\
+ \\
\text { Economia } \\
\text { Farmácia } \\
\text { Geologia } \\
\text { (10) }\end{array}$ & Em execução & $\begin{array}{c}2015 \text { - } \\
\text { presente }\end{array}$ \\
\hline
\end{tabular}

Fonte: Elaborado pelas autoras a partir de consulta ao site do Sistema Arcu-Sul: 〈http://sistemaarcusul. mec.gov.br/arcusul/pages/pesquisaexterna/pesquisarCursoExterno.seam». 
Desde o Mexa, foram acrescentados sete cursos e três Estados participantes, ocasionando não apenas a recomposição da Rana e suas articulações, como a busca da otimização dos procedimentos avaliativos. A experiência de aplicação do primeiro ciclo revelou a necessidade de ajustes do Sistema em face dos mais diversos fatores, tais como a duplicidade nacional e regional dos procedimentos de acreditação, a consolidação das ANAs nos moldes regionais, além da uniformização e confiabilidade dos ditames emitidos por pares avaliadores de distintas nacionalidades, como apontaram as Oficinas de Autoavaliação do Sistema ocorridas entre 2012 e 2014. Essas constatações ensejaram que, na aplicação do segundo ciclo, a Rana aprovasse um procedimento alternativo, possibilitando a aplicação simultânea de acreditações nacionais e regionais desde que acompanhadas por observadores e autorizadas previamente por ela, acatando a proposta da Argentina.

Com a regulamentação do procedimento alternativo, a segunda e última versão do Manual de Procedimentos do Sistema de 2015 traz duas opções para a implementação do procedimento de avaliação externa: a implementação dos procedimentos do Sistema Arcu-Sul ou a solicitação de autorização da Rana para conduzir as acreditações Arcu-Sul simultaneamente às acreditações nacionais, com validade de seis anos.

O novo procedimento envolve duas fases, a pré-autorização e a pósautorização; na primeira delas, a solicitação de autorização deve ser feita pela ANA do Estado interessado ao pleno da Rana. Uma vez recebida a solicitação, a Rana designará, pelo menos, dois observadores de diferentes Estadosmembros do bloco, integrantes das ANAs de sua nacionalidade e capacitados para atuar no Sistema Arcu-Sul, para acompanhar um primeiro processo de avaliação levado a cabo pela ANA requisitante a fim de observar o processo de acreditação. Para tanto, deverá ser utilizado um guia dos aspectos a serem observados, aprovado pela Rana. A partir do informe dos observadores, a Rana poderá: aprovar a solicitação, requerer à ANA requisitante ajustes ou informes adicionais ou denegar a solicitação. Obtida a autorização, a segunda fase tem início no momento em que forem lançadas as convocatórias nacionais de acreditação para cursos contemplados em ambos os sistemas, devendo compor os Comitês de Pares três avaliadores do Sistema Arcu-Sul de diferentes nacionalidades. 0 número de pares estrangeiros deve corresponder ao número de cursos envolvidos, promovendo-se a rotatividade da nacionalidade dos pares na medida do possível, devendo o nome destes ser comunicado à Rana. O Comitê atuará conjuntamente e de forma integrada na avaliação, focando- 
se os pares estrangeiros nos critérios do sistema regional e no respectivo guia de pares (MERCOSUL, 2015).

No tocante ao procedimento original, o fluxograma do processo de acreditação, com todas as suas etapas e prazos, permanece o mesmo, com a duração aproximada de 14 meses, da convocatória até os atos finais, isto é, a informação do resultado às IES, à Rana e à RME. Uma das contemporizações trazidas para os procedimentos internos diz respeito à elaboração de um calendário bianual para as convocatórias, acarretando a não obrigatoriedade de lançamento de convocatórias simultâneas pelos Estados, devendo apenas ser expedidas no biênio indicado, o que favoreceria a implementação do procedimento alternativo.

O Plano de Ação 2016-2020 está disponível apenas no formato de uma tabela de Excel em que constam colunas relativas aos itens: Eixo, Objetivos, Prioridade, Objetivos Específicos, os semestres indicados para a consecução das ações e, por fim, recursos técnicos e/ou financeiros.

Relativamente às incumbências da Rana, o Plano prevê a expansão do Sistema Arcu-Sul, tanto no número de países participantes como de cursos e IES, colocando como metas incrementar em 30\% o número de cursos avaliados e em $100 \%$ o número de acreditações concluídas em cada país no segundo ciclo. Para os três últimos cursos incluídos (Economia, Farmácia e Geologia), são prescritos a elaboração de critérios de qualidade e o lançamento de convocatórias. Também a cargo da Rana ficou a tarefa de desenhar um projeto de avaliação contínua do Sistema, provavelmente com o intuito de sistematizar as meta-avaliações realizadas pela própria Rede desde o Mexa, e a de desenhar e implementar ao menos dois projetos de assistência técnica em matéria de acreditação, solicitando financiamento por meio de recursos centrais do Mercosul ou fontes alternativas. Por fim, o Plano vislumbra a realização de atividades de cooperação e promoção de boas práticas entre os Estados da Rede (MERCOSUL, s/d).

Como se pode observar, as atividades e responsabilidades da Rana têm se multiplicado à medida que o Sistema Arcu-Sul galga passos para se tornar um processo de acreditação de cursos de graduação de status efetivamente regional, tanto na abrangência de carreiras como na de participantes, moldando-se a cada novo entrave. Insta notar que, no Plano 2016-2020, as ações da Rana são associadas às da União das Nações Sul-americanas (Unasul) e à Agenda 2030 da Organização das Nações Unidas (ONU) no que 
diz respeito à qualidade da educação, denotando a intenção de legitimar o Sistema Arcu-Sul em âmbito internacional para além do bloco.

\section{CONSIDERAÇÕES FINAIS}

A figura peculiar da Rana emerge da construção conjunta de Estados considerados periféricos que intentam enfrentar as tendências impostas à mobilidade profissional e acadêmica num cenário de mudança de século a partir da dinâmica de um bloco econômico regional intergovernamental.

Sua natureza coletiva sui generis advém do fato de que suas decisões serão aplicadas pelos entes que a compõem, imprimindo-lhes, desta feita, maior legitimidade. Partindo-se dessa premissa, pode-se inferir que a implementação do processo de acreditação do Mercosul não se configura nos moldes tradicionais, haja vista que a prática política e a administrativa mesclam-se em função de seus atores, que em âmbito nacional agem individualmente e, no regional, em rede. Essa interface propicia que ajustes sejam feitos sempre que considerados necessários via deliberação, como o procedimento alternativo para a realização da avaliação externa nacional e regional conjunta.

À medida que o Sistema Arcu-Sul se expande, se por um lado a Rana se consolida como órgão do SEM, por outro dela é exigido um leque maior de atividades que demandam não apenas seu melhor aparelhamento, como também recursos financeiros e humanos, considerando-se, notadamente, a projeção de ampliação do Mexa em relação ao segundo ciclo de acreditações do Sistema Arcu-Sul.

Não obstante alguns Estados ainda não possuam ANAs consolidadas no modelo regional, como no caso do Brasil e do Uruguai, no estágio hodierno do Sistema Arcu-Sul pode-se depreender que as atividades da Rana, de forma geral, dificilmente seriam prejudicadas. Todavia, cabe ressalva à fase de implementação do Sistema para os novos Estados participantes, resgatandose que a falta de operosidade adequada das ANAs poderia colocar em risco ações voltadas para a educação superior.

Deve-se sopesar, todavia, que a participação de novos Estados a cada ciclo acarreta, potencialmente, a alteração da configuração das forças de poder nas tomadas de decisão da Rana, refletindo-se diretamente na condução do Sistema. 
Por fim, cabe considerar que as projeções de expansão para o Sistema Arcu-Sul trazidas no Plano 2016-2020 anunciam sua aplicação em escala subcontinental, atrelando as ações da Rana à Unasul, integrada por todos os Estados da América do Sul que, igualmente, de alguma forma, participam do Mercosul, seja como membros ou como associados. 


\section{The National Accrediting Agencies Network and the management of the ARCU- SUR System}

Abstract: This study aims to analyze the Network of National Accreditation Agencies' (RANA) performance in managing the MERCOSUR Accreditation System for Undergraduate Courses (ARCU-SUR System). The RANA is formed by officials representing the National Accreditation Agencies of each member state. The main challenges in RANA's activities range from designing indicators to mark the quality of courses in different higher education systems to adjusting the network's composition as new member states join in. Bibliographic and documentary research techniques were used, as well as interviews with people who participated in the System's creation or in actions related to RANA. We found that the experience of managing the System allowed RANA to review and flexibilize some positions in order to operationalize the System's consolidation.

Keywords: Accrediting Agencies Network. Mercosur Educational Sector. ARCUSUR System. 


\section{La Red de Agencias Nacionales de Acreditación y la gestión del Sistema Arcu-Sur}

Resumen: Se pretende analizar la actuación de la Red de Agencias Nacionales de Acreditación (Rana) en la gestión del Sistema de Acreditación Regional de Carreras Universitarias del Mercosur (Sistema Arcu-Sur). La Rana está compuesta por representantes de las Agencias Nacionales de Acreditación de los Estados participantes en el Sistema. Los principales desafíos de la actuación de la Rana incluyen desde la concepción de indicadores capaces de señalar la calidad de los cursos pertenecientes a sistemas de educación superior diferentes hasta su recomposición por la adhesión de más Estados. Se utilizaron técnicas de investigación bibliográfica y documental, además de entrevistas con personas que participaron en la elaboración del Sistema o en acciones relacionadas con la Rana. Se pudo observar que la experiencia de gestión de la ejecución del Sistema posibilitó a la Rana revisar y flexibilizar algunos posicionamientos con el fin de operacionalizar la consolidación del Sistema.

Palabras clave: Red de Agencias Nacionales de Acreditación. Sector Educativo del Mercosur. Mercosur. Sistema Arcu-Sur. 


\section{REFERÊNCIAS}

ANDRÉS, A. A educação superior no Setor Educacional do Mercosul. Brasília: Biblioteca Digital da Câmara dos Deputados, 2010. Disponível em: «http:// bd.camara.gov.br/bd/bitstream/handle/bdcamara/6044/educacao_ superior_andres.pdf? sequence=1〉. Acesso em: 4 jul. 2011.

BARREYRO, G. B.; HIZUME, G. C. O sistema de acreditação regional de cursos universitários do Mercosul (Sistema Arcu-Sul). In: TAUCHEN, G.; FÁVERO, A. A. (Org.). Coleção Avaliação do Ensino Superior: perspectivas mundiais, v. 1, p. 27-41, 2017.

FULQUET, G. A. El proyecto educativo para el Mercosur y los debates en torno a la internacionalización de la educación superior. Buenos Aires: Centro Argentino de Estudios Internacionales (Caei), 2006.

GUILAYN, P.M. Diagnóstico estratégico da rede de agências nacionais de acreditação gestora do Sistema de Acreditação de Cursos Universitários do Mercosul (Arcu-Sul). 2012. 116 f. Dissertação (Mestrado em Administração Pública)-Universidade de Brasília, Brasília, 2012.

HERMO, J. P. La acreditación regional de carreras en el Mercosur: presente e futuro. Saarbrücken: Editorial Académica Española, 2011.

HIZUME, G. C. Apontamentos sobre a configuração da Comissão Nacional de Avaliação da Educação Superior como Agência Nacional de Acreditação no Sistema Regional de Acreditação de Cursos Universitários do Mercosul Sistema Arcu-Sul. 2010. 39 f. Monografia (Conclusão de Curso)-Curso Latinoamericano de Especialização em Políticas Públicas e Avaliação do Ensino Superior, Universidade Federal do Paraná/Universidade Federal da Integração Latino-americana, Foz do Iguaçu, 2010.

A implementação do Sistema de Acreditação Regional de Cursos Universitários do Mercosul: um estudo sobre as Agências Nacionais de Acreditação da Argentina e do Brasil. 2013. 264 f. Dissertação (Mestrado)Programa de Pós-graduação em Integração da América Latina, Universidade de São Paulo, São Paulo, 2013.

; BARREYRO, G. B. O mecanismo experimental de acreditação do Mercosul (Mexa): a construção de um processo regional de certificação de qualidade de cursos de graduação. Revista Internacional de Educação Superior, Campinas, v. 3, n. 1, p. 46-65, abr. 2017. 
MERCOSUL. Comité Coordinador Regional (CCR). Comisión Regional Coordinadora de Educação Superior (CRC-ES). Rede de Agencias Nacionales de Acreditación (Rana). Taller Regional de Autoevaluación del Sistema ArcuSur, 2012.

- Manual Revisado do Sistema Arcu-Sul. Anexo IV da Acta 1/2015 da Rana, 2015.

MERCOSUL EDUCACIONAL. SEM. Plano de Ação 2011-2015, 2011.

. SEM. Plano de Ação 2016-2020, s/d. Disponível em: 〈http://edu. mercosur.int/pt-BR/plano-2011-2015/160-plano-de-acao-2016-2020.html〉. Acesso em: 1ํ jul. 2018.

MERCOSUR EDUCATIVO. SEM. Plano Trienal 1998-2000, 1998.

. SEM. Instancias del Sector Educativo del Mercosur. Disponível em: 〈http://www.edu.mercosur.int/es-ES/mercosul-educacional/instancias.html». Acesso em: 21 abr. 2017a.

. SEM. Que es el Sector Educativo del Mercosur. Disponível em: 〈http:// http://www.edu.mercosur.int/es-ES/mercosul-educacional/o-que-e.htmls. Acesso em: 21 abr. 2017b.

- SEM. Sistema de acreditación de carreras universitarias para el reconocimiento regional de la calidad académica de sus respectivas titulaciones en el Mercosur y Estados asociados. Manual del Sistema 20082010, 2008.

MERCOSUR. Decisión 17/08. Acuerdo sobre la creación y la implementación de un Sistema de Acreditación de carreras universitarias para el reconocimiento regional de la calidad académica de las respectivas titulaciones en el Mercosur y Estados Asociados. Consejo del Mercado Común, 2008.

RANA. Ata 02/06. Reunião Conjunta de Membros da Comissão Regional Coordenadora de Educação Superior e de Agências Nacionais de Avaliação e “Credenciamento” ou Equivalentes, realizada em 3 nov. 2006.

Sistema Arcu-Sur. Manual de Procedimientos del Sistema, 2015.

SISTEMA ARCU-SUR. Convocatorias acutales. Disponível em: <http://edu. mercosur.int/arcusur/index.php/es/convocatorias-actuales». Acesso em: 9 jul. 2018. 
Gabriella de Camargo Hizume é doutoranda em Educação pela Universidade de São Paulo (USP). Atualmente é docente do curso de Direito da Universidade Estadual do Oeste do Paraná (Unioeste), campus de Francisco Beltrão, Paraná, Brasil.

E-mail: gabriellahizume@usp.br.

Gladys Beatriz Barreyro é doutora em Educação pela Universidade de São Paulo. Atualmente é professora da Escola de Artes, Ciências e Humanidades da Universidade de São Paulo - Each-USP, São Paulo, Brasil.

E-mail: gladysb@usp.br.

Recebido em: julho de 2018

Aprovado em: julho de 2018 